\title{
Survey of Cellular Signal Booster
}

\author{
Elizabeth N. Onwuka \\ Telecom. Engineering Research Group, Federal University of Technology Minna, 920211, Nigeria \\ Email: onwukaliz@ futminna.edu.ng \\ Michael Okwori, Salihu O. Aliyu, Stephen S. Oyewobi, Caroline O. Alenoghena, \\ Habeeb Bello-Salau, Sani S. Makusidi, Victor Asuquo \\ Telecom. Engineering Research Group, Federal University of Technology Minna, 920211, Nigeria \\ Email: \{michaelokwori, salihu.aliyu, carol, habeeb.salau, oyewobistephen\}@ futminna.edu.ng, \\ \{sani.makusi, victorasuquo\}@ gmail.com
}

Received: 25 May 2018; Accepted: 02 October 2018; Published: 08 November 2018

\begin{abstract}
The development of wireless technology has facilitated the wide deployment of mobile communication systems. The beauty of wireless communication is that all nooks and corners can be reached at a cheaper and faster rate when compared with wireline. Wireless is now dominating the telecommunications market. Initially, the dawn of wireless was seen as the dawn of communications to poor countries and rural areas which were poorly covered by wireline devices due to high cost. Currently, the story has changed. Both the wired and unwired environments are clamoring for wireless connectivity. Considering the hype of $R \& D$ in broadband technologies and easy acceptance in the market place, wireline communications may soon die a natural death. However, wireless communications faces a few challenges. One of them is that the radio frequency (RF) carrier signals used in these communication systems degrades as it travels through the air interface due to attenuation and interference. As a result, the range of coverage may not be as planned leading to very weak reception or even dead zones where no communication can be done. This problem has resulted in the development of cellular signal boosters that help in receiving the weak signal, amplifying and then re-transmitting it to reach the uncovered areas. Boosters are now giving hope to the frustrated wireless users such as indoor users and those at the fringes of a cell site. These boosters are diverse in make, range, method of operation, deployment and cost. In this paper, a survey of various signal booster designs, deployment and performance is presented. It is hoped that this will serve as a one-stop shop for researchers and developers in the important field of wireless signal boosters and extenders, who wish to know what is available and existing challenges.
\end{abstract}

Index Terms-Boosters, Repeaters, Cellular Signal Degradation, Weak Signal Reception, Cellular Generations

\section{INTRODUCTION}

Mobile communication have not only made the sharing of knowledge and information easy but have brought with it socioeconomic benefits. It has made possible services such as online banking, social networking, online markets, internet job markets and etc. All of these have contributed to making the Telecommunication Industry a major contributor to the gross domestic product (GDP) of many countries both the developed and the developing [1]. In general, wireless communications has cut down the cost of living and doing business in several ways.

These benefit have created a huge demand for the services prompting Mobile Network Operators' (MNO) massively deploying network coverage to urban and some rural areas. This supports the projection that worldwide traffic by 2020 should reach about 33 times increase from figures obtained in 2010 [2]. This deployment of networks is usually done with emphasis on maximizing profit and as a result, coverage and services provided are optimized for areas where commensurate revenue can be generated leading to neglect and no or poor service provided to non-profitable regions [3]. Even priority regions can also experience weak signal reception as a result of radio frequency signal degradation due to additive noise in the wireless channel and signal fading due to either multi-path propagation or shadowing from obstacles that distort the propagation of the radio wave [4]. These obstacles can be natural such as valleys and intervening mountains, and also manmade such as tunnels, subway station or underground parking [5]. In fact, priority areas such as major cities suffer a good deal from weak signal reception due to poor signal propagation along narrow streets with tall buildings and indoor penetration losses. Also, the continuous broadening of bandwidth of mobile systems can lead to frequency selective fading resulting 
in smaller cell sizes [6]. All of this creates regions with weak signal strength (WSS) making communication to be not possible or a huge drop in the Quality of Service (QoS) provided.

Weak Signal Strength is prevalent at the edges of networks in urban areas and even suburban areas, which are also with a rapidly growing demand for communication services [7]. Also certain portions/offices in buildings in urban areas can degrade the received signal to the extent of making communication impossible [8]. The few rural areas that have networks deployed can have an entire settlement situated away from the site of the network access. The reason for this comes from the fact that low user density in rural areas necessitates wider (macro) cells, the design of which may place some settlements at the fringe or entirely outside the coverage. Weak signal reception also leads to quick depletion of cell phone batteries. At the same time it greatly increases that power flux radiation from the user device, which has the added challenge of being harmful to health. The problem of weak signal reception is multifaceted, and can deprive individuals and communities from enjoying the tremendous benefits of living in a connected world. Therefore, viable solutions are crucial hence the investment in $\mathrm{R} \& \mathrm{D}$ for signal boosters.

Two classes of device can be used to extend coverage and combat WSS, these include: layer-1 devices, which simply amplify-and-forward (AF), and layer-2 devices that decode-and-forward (DF) [9, 10]. The AF devices, commonly referred to as signal boosters, repeaters or cell enhancers, are a very viable and cheap solution. They simply receive the weak signal, amplify it and then re-transmit to cover more areas $[5,11]$. The DF devices, commonly referred to as relays, on the other hand can provide additional features such as noise propagation mitigation and link adaptation, but are more intricate in design. Another perspective presents relays as operating in two modes AF and DF [12]. A performance evaluation of AF and DF relays in LTE-Advanced network is presented in [13]. This paper presents a survey of cellular signal boosters

The rest of the paper is structured as follows: Section 2 presents an overview of signal boosters, highlighting antenna selection problem; design and operation challenges; basic booster standards specifications among others. Section 3 presents research efforts in booster technology in the various generations of cellular communication technology. While the paper is concluded in Section 4, where some open issues in booster technology are highlighted.

\section{Cellular Signal Booster}

Cellular Networks are wireless communication networks in which the total region of coverage are divided into smaller regions of coverage called cells. Access to the network is provided to each cell by access points that transmit RF signals at specific frequency ranges. These access points are commonly called base stations (BS).This system can be highly efficient as it enables the reuse of the frequency spectrum and conservation of power at the base stations [14]. The cells are designed to overlap, as shown in Fig. 1(a), this facilitates the handover of a mobile user from one cell to a neighboring cell as the user moves from one region of coverage to another. This is usually not the case with poorly designed cellular sites (see Fig. 1(b)) and optimized cellular networks increases the probability of the existence of dead zones or zones with poor received signal strength due to the proliferation of edges. Cellular Signal Booster is a very efficient solution to this problem.

Cellular Signal Boosters are devices deployed in cellular networks to primarily assist in reestablishing connection between mobile nodes and BS in regions of weak signal reception. They can also be used to extend cell coverage range by amplifying and re-transmitting the weak signal from the BS along desired directions [15]. These repeaters have found very useful applications in the various generations of cellular networks as signal degradation is common to all generations, though with varied impact. In this section, we present the basic operation of boosters, highlighting antenna selection problem, design and operational challenges, including basic booster standards specifications among others.

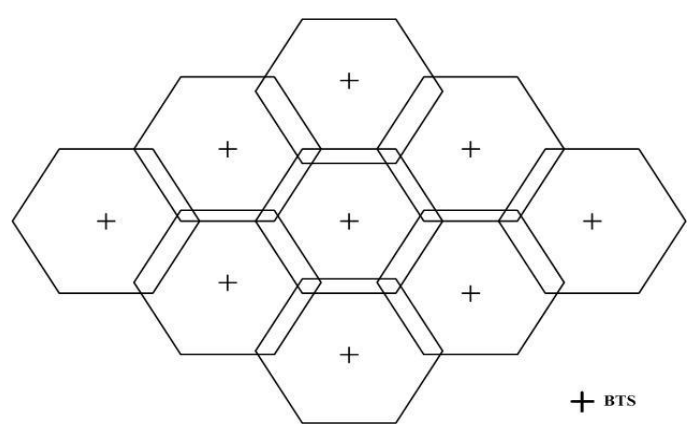

(a). Good Cell

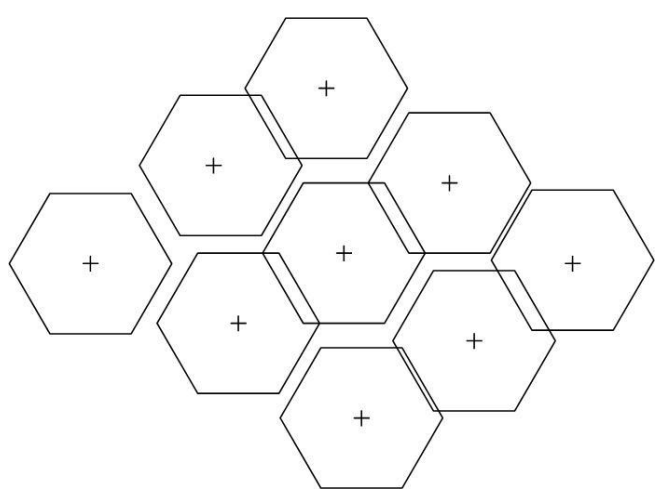

(b). Poor Cell

Fig. 1. Example of good and poorly planned cellular sites 


\section{A. Basic Operation of Boosters}

A typical RF signal booster is made up of four functional units that are interconnected as shown in Fig. 2. The receiving antenna is responsible for capturing the weak and degraded RF signal to be amplified, which is then passed onto the post-amplification stages. The post amplification processes carried out depends, to a large extent, on the type and capabilities of the of the RF booster. Typical processes carried out in this stage involves received signal filtering, frequency multiplication, analog to digital conversion, and feedback cancelation. The post-amplification processing may involve digital to analog converter, transmitter, filter, and attenuators. In between these two is the amplifier responsible for increasing the strength of the weak signal [16]. The amplifier can be a series of different stages, for example a low noise front-end responsible for amplifying the RF signal with low noise, an intermediate frequency (IF) block responsible for amplifying the IF UHF that the RF frequency is stepped down to, and finally the power stage that amplifies the original RF signal after the IF is up-converted before radiating into space [17].

The booster can be deployed for both outdoor and indoor applications. For the outdoor application, both the receiving and the transmitting antenna are situated outdoor and the amplified weak signal can be utilized by users in the region of coverage of the transmitting antenna. Such scenarios are common where the network needs to be extended to dead zones and localities with a good number of users. They are usually deployed by the Network Operator to optimize profit as this is done at a cost much less than deploying more BS to cover areas with weak signals[17, 18]. For the indoor application, the receiving antenna is placed outdoor, usually at an elevated position to receive the weak signal, while the transmitting antenna is deployed inside the building. This way, users in buildings get to enjoy quality communication services.

\section{B. Classification of Boosters}

Signal boosters can be categorized into various groups, depending on criteria such as range of coverage, duplexing type, antenna deployment, functionality, and spatial streams. Fig. 3 shows the classification topology while a brief discussion on each type follows. Based on the range of coverage, boosters can cover from a few meters to several kilometers. The range of coverage depends on factors such as power and gain of transmitter, as well as the directivity. The range can be limited to small spaces for covering a single room, medium spaces for servicing of entire home or office space, large spaces for applications in large office buildings, warehouses and

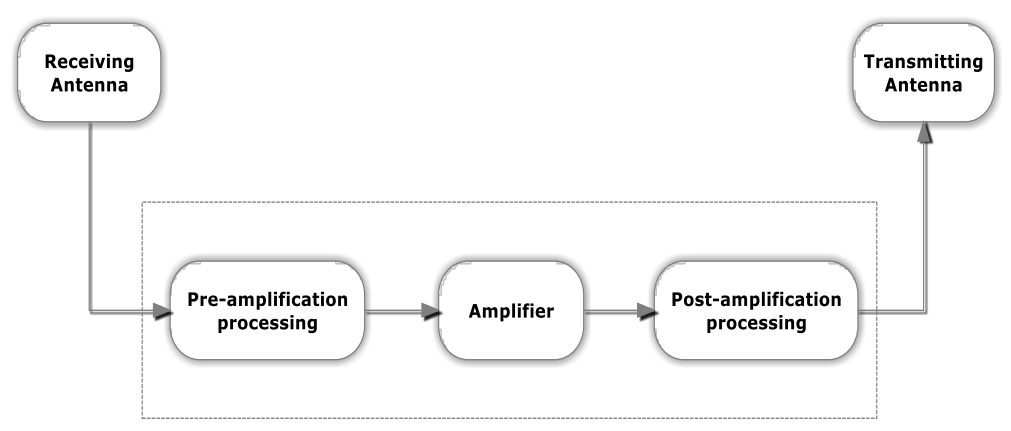

Fig. 2. Basic Block of an RF booster

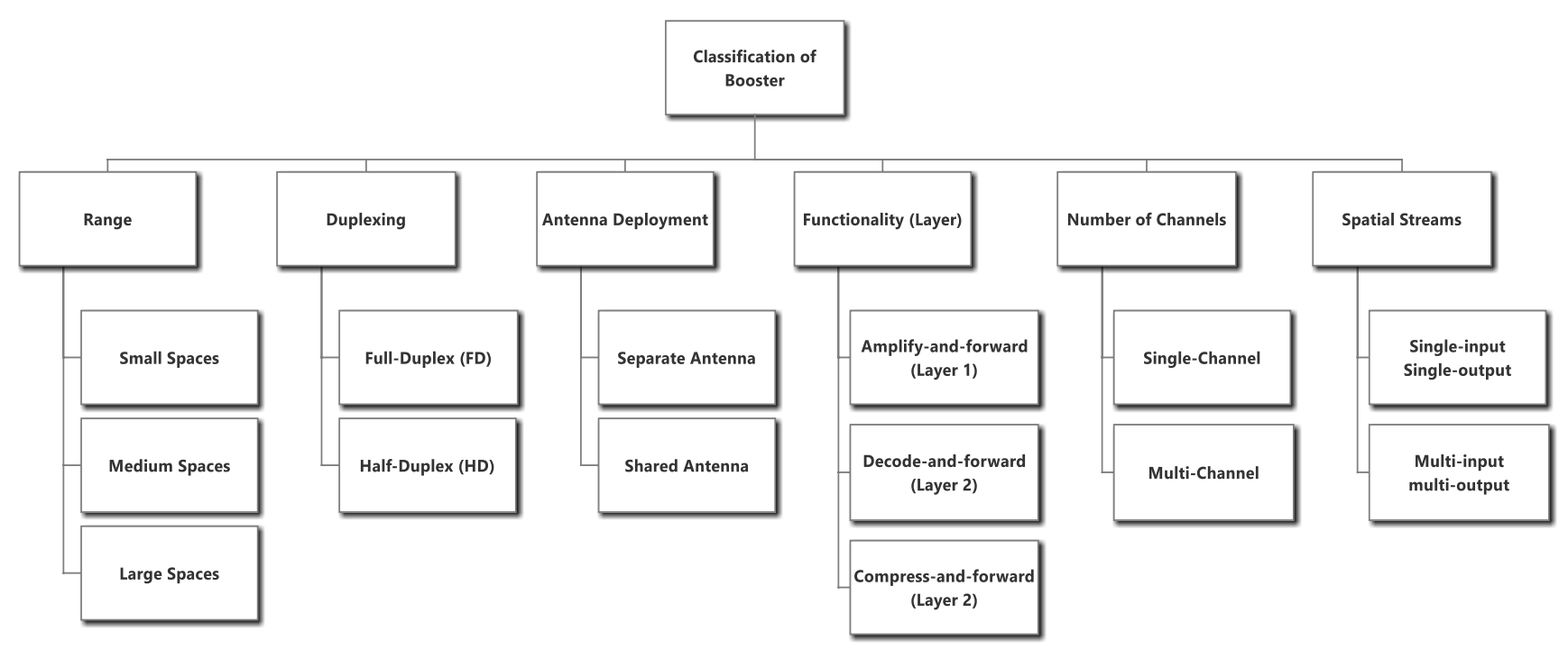

Fig.3. Classification of Boosters 
remote areas. Another criteria used to classify boosters are the duplexing type, which can be Full-Duplex (FD) repeaters and Half-Duplex repeaters (HD). FD repeaters are capable of boosting both the forward and reverse links, while HD repeaters can only boost either the forward or reverse link. Active research is ongoing to develop in-band FD repeaters that will use the same frequency spectrum for both links $[2,10,12,19]$, in this class, the duplexing will be done in time. Antenna deployment of both the donor/receiving and the transmitting antennas can either be co-located on a single antenna or be separated. For the shared co-located antenna systems, they are compact and easy to install, but intricately designed to handle self-interference issues. The separate antenna systems are more common, and usually have a directional donor antenna, mounted in the line of sight of the serving base transceiver station (BTS) and an isotropic transmitting antenna in the area of the users. Some repeaters operate at layer-1 and only amplify-and-forward the signals while others are layer-2 devices that have capabilities of to decode-and-forward and compress-and-forward [20]. The layer-1 repeaters are simple in design, but can also propagate noise in the system, while the layer-2 are complex and tend to introduce more delay in the system, but can isolate and amplify the signal only [21]. There are also repeaters that are only single channel that supports only one user at a time, and others that are multi-channel and can support more than one user at a time. Based on the amount of spatial streams, repeaters can be single-input single-output which have one donor antenna and one transmitting antenna or multi-input multi-output that have more than one antenna at both ends.

\section{Antenna Selection}

Antenna are transducers that convert radio frequency electric current to electromagnetic waves that are then radiated into space. Due to the reciprocity exhibited by antennas, they can also convert electromagnetic waves back to radio frequency electric current. Antennas can be in assortment of shapes and sizes, with properties such as feed-point impedance, directivity, gain, efficiency and polarization playing important roles in determining performance [22,23].

Two types of impedance are exhibited by antennas, self-impedance (measured completely away from sources of interference) and mutual impedance (in the presence of parasitic effect of nearby conductors). The self-impedance is equivalent to the ratio of the voltage across its feed-point to the current flowing into it. The antenna impedance is not usually a pure resistance, but made up of either capacitive or inductive reactance in series with a resistance. For efficient radiation of electromagnetic energy, the feed-point impedance must be matched to the driving circuit impedance, and this is usually achieved with a matching circuit between the two. An automatic impedance matching and antenna tunning using quantum genetic algorithms is reported in [22].

Another factor of consideration is the directivity of the antenna. A directional antenna has maximum gain in a specific direction while omni-directional antenna have equal gain in all directions. For most cellular boosters, the receiving antenna is a directional antenna that is mounted pointing at the direction of the BTS of the weak signal while the transmitting antenna is an omni-directional one radiating is all directions to ensure users are not limited to a particular section of area of deployment. This arrangement helps to increase the isolation between the antennas.

Another important antenna consideration is the isolation between the receiving antenna and the transmitting antenna. To avoid self-amplification resulting in system instability, it is recommended that the isolation between the two antennas be greater than the gain of the system. Recommended isolation of $15 \mathrm{~dB}$ higher than the repeater gain is reported in [11], while [24] used an isolation within the range of $85-95 \mathrm{~dB}$. To achieve this, a couple of methods have been employed, ranging from deployment of the two antenna in either vertical, horizontal or at $90^{\circ}$ orientation depending on the one with the maximum attenuation, increasing the physical distance separating the antennas, situation of obstructions between them to increase the shielding factor [11]. Equation (1) represents the approximate isolation between the antennas.

$$
I s o=32.44+20 \log (d)+20 \log (f)+T x_{\text {loss }}+R x_{\text {loss }}
$$

where $d$ is the distance separating the two antennas in meters, $f$ is the frequency of communication in $\mathrm{MHz}$, $T x_{\text {loss }}$ is the attenuation of the transmitter in the direction of the receiver and $R x_{\text {loss }}$ is the attenuation of the receiver in the direction of the transmitter.

Polarization is also crucial and is the direction in which the strength of the field is maximum and can either be vertical or horizontal, a combination of horizontal and vertical or indeterminate. Another important factor to consider is that the frequency range of optimum performance of selected antenna must lie in the frequency band of the RF signal of interest. For cellular boosters, the antenna selected must have its stated optimum frequencies in the frequency band of the channel to be amplified. A choice also needs to be made as regards the number of antennas to deploy at the transmitting end. For indoor application, a distributed antenna system (DAS), comprising of multiple antenna connected to the booster via splitters and tappers, can be used to cover different parts of buildings. This can help to greatly expand the coverage range of booster as against what is obtained when a single antenna system is deployed [25].

\section{Design and Operation Challenges}

Repeaters are good and cheap means of increasing coverage and performance of cellular networks, but can also introduce undesirable effects such as interference, particularly in the uplink [26,27], and also cause a jam in the network. All of which can result in expensive troubleshooting by mobile operators and service degradation to subscribers [16]. As such, special attentions is paid to ensure proper design and deployment 
to overcome negative challenges of boosters in networks. This sub-section highlights design and operational challenges of cellular boosters. A very paramount consideration in the design of boosters is the need for good isolation between the transmitting antenna and receiving antenna. This is to prevent the system going into self-amplification that can block out the desired signal [28]. This isolation puts a limit on the gain of the booster which is designed to be less than the isolation. Also deployment of boosters in areas with a good signal reception can result in quality degradation [29] as a result of the two signals combining with different delays in the user device, thereby increasing inter-symbol interference (ISI) [5]. It is important that one BTS is isolated and its signal amplified into the region of weak coverage. This can be achieved with the use of narrow beam-width antenna as receiving antenna on repeaters [29].

\section{E. Cost Determinants}

A wide variety of booster are available in the market with price ranging from cheap to pretty expensive. The cost of a booster, to a large extent, is dependent on its specification, and to a lesser extent, on the manufacturer. Table 1 shows some samples of the boosters in the market, their manufacturers, specifications and prices. A close inspection of the Table shows that boosters can be designed for a particular MNO, as in the case of Phonelex Cell Phone Signal Repeater Booster Amplifier which was designed specifically for band 13 Verizon $700 \mathrm{MHz} 4 \mathrm{G}$ LTE $70 \mathrm{~dB}$ cellular band as stated by the manufacturer. A good check to run when a booster is not designed for a specific MNO is to confirm that its frequency range of operation covers the particular MNO of the user.

Table 1. Sample Boosters in Market with Specifications

\begin{tabular}{|c|c|c|c|}
\hline Booster Name & Manufacturer & Description by Manufacturer & Price \\
\hline $\begin{array}{l}\text { weBoost Connect } 4 \mathrm{G} \\
\text { Cell Phone Signal } \\
\text { Booster }\end{array}$ & weBoost & $\begin{array}{l}\text { Perfect for mid-sized homes. Boosts cell signals up to } 32 \mathrm{x} \text {. Enhances } 4 \mathrm{G} \text { LTE and } 3 \mathrm{G} \text { signals } \\
\text { for buildings up to } 5,000 \text { sq ft. Get fewer dropped calls, better voice quality, faster uploads } \\
\text { and downloads. Compatible with all US networks and with all cellular devices. PATENTED } \\
\text { AUTOMATIC GAIN SETTINGS: Smart technology senses signal conditions in and around } \\
\text { the building, then electronically optimizes the booster for best performance. }\end{array}$ & $\$ 539.99$ \\
\hline $\begin{array}{l}\text { SureCall EZ } \quad 4 \mathrm{G} \\
\text { Plug-and-Play } \quad \text { Cell } \\
\text { Phone Signal Booster }\end{array}$ & SureCall & $\begin{array}{l}\text { Sets up in minutes - simple plug-and-play install. Boosts voice, text and 4G LTE signals for } \\
\text { all North American cell carriers. Reduces dropped \& missed calls and supports multiple users } \\
\text { simultaneously. Coverage area will vary based on existing signal at the window location } 1-2 \\
\text { Bars } \sim 500 \mathrm{sq} \mathrm{ft,} 3-4 \text { Bars } \sim 1000 \mathrm{sq} \mathrm{ft}, 5 \text { Bars } \sim 2000 \mathrm{sq} \mathrm{ft}\end{array}$ & $\$ 317.99$ \\
\hline $\begin{array}{l}\text { Phonelex Cell Phone } \\
\text { Signal Repeater } \\
\text { Booster Amplifier }\end{array}$ & Phonelex & $\begin{array}{l}\text { Designed for band } 13 \text { Verizon } 700 \mathrm{MHz} 4 \mathrm{G} \text { LTE } 70 \mathrm{~dB} \text { cellular band, Much faster high-speed } \\
\text { 4G LTE internet. Perfect for fast uploads and downloads for streaming apps such as Google } \\
\text { Chrome, Safari, YouTube, Netflix, Pandora, Spotify, and other data-heavy apps. Works for } \\
\text { Verizon } 70 \mathrm{~dB} 700 \mathrm{MHz} 4 \mathrm{G} \mathrm{LTE} \text {. Supports any phones for any Wireless Carriers in the } \\
\text { frequency range : } 776-787 \mathrm{MHz} \text { and } 746-757 \mathrm{MHz} \text {. Used for village, garage, basement, } \\
\text { home, office, hotel, apartment etc. }\end{array}$ & $\$ 159.99$ \\
\hline $\begin{array}{l}\text { ANNTLENT GSM } \\
850 \mathrm{MHz} \text { 3G Repeater } \\
\text { Cellphone Signal } \\
\text { Booster }\end{array}$ & Anntlent & $\begin{array}{l}\text { Frequency Range (MHz): 824-849; } 869-894 \text { Max Gain (dB): } 65 \text {; Max output power (dBm): } \\
\text { 15dBm; I /O Port: SMA-Female; Power Supply: input AC100 } 240 \mathrm{~V} 50 / 60 \mathrm{~Hz} \text {, output DC 5V } \\
\text { 0.35A. }\end{array}$ & $\$ 113.99$ \\
\hline $\begin{array}{l}\text { Phonetone GSM 3G } \\
\text { 850MHz Phone Signal } \\
\text { Repeater }\end{array}$ & Phonetone & $\begin{array}{l}\text { Frequency range: } 824 \sim 849 \mathrm{MHz}, 869 \sim 894 \mathrm{MHz} \text { Max Output Power: } 22 \mathrm{dBm} / \text { Max Gain: } \\
62 \mathrm{~dB} \text {; I/O Port: N-Female on both ends FCC authentication certificated Verizon /T-Mobile } \\
\text { USA/AT\&T /Sprint /boost /MetroPCS /Big River /Cincinnati Bell }\end{array}$ & $\$ 98.98$ \\
\hline
\end{tabular}




\section{F. Good/Poor Booster Technology}

For a booster to be able to provide good service to the users, the technology of development must be sound and made to cater for factors that can diminish performance. One of those factors is that it should be stable and have a good gain. The isolation between the two antennas should be greater than the total gain of the system. This will prevent the system going into oscillation and degrading service provided. The gain of the booster also should be reasonable enough to cover the area of location of expected users. When a single antenna is not enough to cover the desired area, a DAS can be used to reach all the locations of users. Another important factor of consideration is the amount of noise introduced into the system, this is more of a worry for AF boosters, than other higher level booster that have the capability of isolating and boosting the required signal without introducing noise into the system.

\section{G. Booster for Nigerian Environment}

The last decade in Nigeria has witnessed exponential growth in the use of wireless cellular communication. This trend is likely going to continue with the Nigerian Communications Commission (NCC) statistics indicating more than 96.6 million active users, a good number of whom are in high population density cities and a small fraction in rural and suburban areas. Due to poor landline connectivity, there is a heavy reliance on mobile communication systems, placing a huge demand for GSM services. The mobile operators are hardly able to satisfy this high demand. Consequently, many areas suffer from weak or no signal reception. This have resulted in a progressive decline in the QoS experienced by users. Also the Nigerian terrain comprises of hills, valleys, plateaus and a few high rise structures that can block out signal, and cause weak signal reception (WSR). Poor planning and deployment of networks by MNO in Nigeria have also left a lot of holes in areas with a good number of potential users [14].

The use of cellular boosters in Nigeria is a growing trend that is not only beneficial to the users but can help maximize profit by operators. The NCC recently put out a warning on boosters deployed indiscriminately by users, stressing that users can only deploy boosters in conjunction with licensed network operators [30]. A lot of these boosters are currently imported and on sale in the Nigerian Market. Local design and production of these devices will go a long way in saving scarce foreign exchange, create employment opportunities, and enhance man-power skill development. This is the ultimate goal of this research. Moreover, designing boosters locally is very beneficial in the sense that local signal propagation behaviors and local environmental factors affect performance of these systems.

\section{H. Basic Booster Standards Specifications}

Boosters are required to meet standard specifications stipulated by authorizing bodies. Cellular boosters in Europe, for example, are to be compliant with European Telecommunications Standards Institute (ETSI) documents that provide guiding specifications for UMTS systems. Table 2 shows the main ETSI specifications that the repeater designed in [17] was complaint with.

Table 2. Booster Specifications

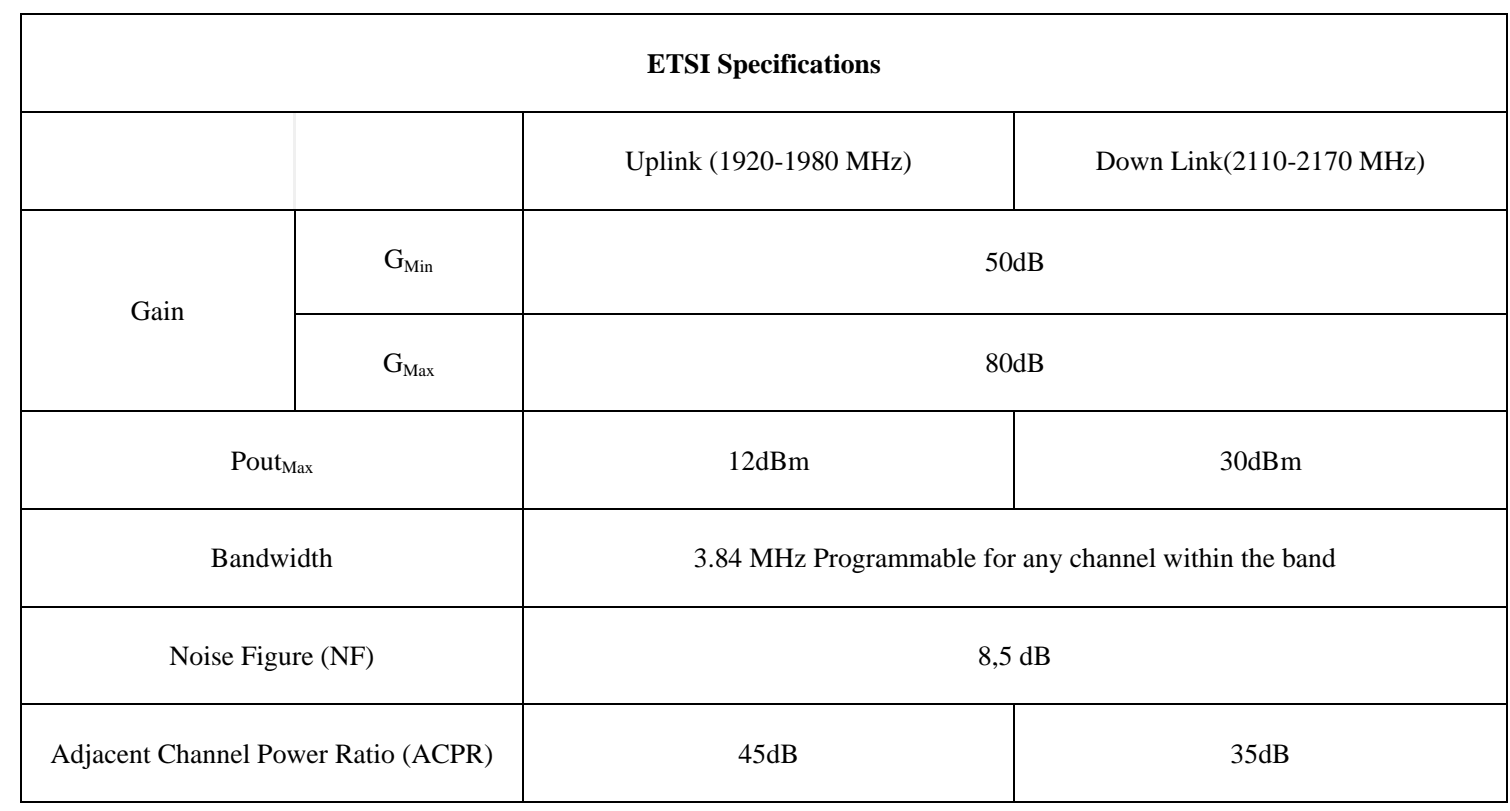


Table 3. Common ETSI Specifications for Repeaters

\begin{tabular}{|c|c|}
\hline Test Parameter & Specification \\
\hline $\begin{array}{l}\text { Effective Power of } \\
\text { Spurious Emissions }\end{array}$ & $<-36 \mathrm{dBm} 250 \mathrm{nW}$ ) in the frequency band $9 \mathrm{kHz}$ to $1 \mathrm{GHz}$ \\
\hline $\begin{array}{l}\text { Maximum Level of } \\
\text { Intermodulation Product }\end{array}$ & $<-36 \mathrm{dBm} 250 \mathrm{nW}$ ) in the frequency band $9 \mathrm{kHz}$ to $1 \mathrm{GHz}$ \\
\hline Net Gain in both directions & $\begin{array}{l}-50 \mathrm{~dB} \text { at } 400 \mathrm{kHz} \text { offset and greater; - } 40 \mathrm{~dB} \text { at } 600 \mathrm{kHz} \text { offset and greater; }-35 \mathrm{~dB} \text { at } 1 \mathrm{MHz} \text { offset } \\
\text { and greater; }-25 \mathrm{~dB} \text { at } 5 \mathrm{MHz} \text { offset and greater; from }\end{array}$ \\
\hline Average Frequency Error & The average frequency error of the repeater system shall not exceed $0.1 \mathrm{ppm}$. \\
\hline Phase Error & $\begin{array}{l}\text { <- } 7 \text { degrees rms; - } 28 \text { degrees peak (for complete systems), } 6.1 \text { degrees rms; - } 24.5 \text { degrees peak } \\
\text { (for single repeater unit) }\end{array}$ \\
\hline
\end{tabular}

A good reference for some general ETSI standards for tests to conduct for GSM and DCS are found in [31] where it is stated that manufacturers of repeaters shall declare the band(s) of operation, the maximum rated output power per channel, the number of channels and modulation schemes supported. Some common specifications extracted from [31] are specified in Table 3. Federal communication commission (FCC) also specifies such standards for the US. And, of course, all such regional standards are derived from the international telecommunication union (ITU) family of telecommunications standards. Any booster design is expected to comply with specified standards.

\section{RESEARCH EFFORTS IN REPEATER DESIGN AND DEPLOYMENT}

Repeaters have been successfully investigated and deployed in the $2 \mathrm{G}, 3 \mathrm{G}$ and $4 \mathrm{G}$ networks, and investigations are ongoing for applications in $5 \mathrm{G}$ networks. Figure 4 gives a snap-shot view of the various related works in literature. Some of these briefly discussed below.

Yisheng Xue, in [9], investigated the effect of repeaters on throughput in cellular systems where the random access channels of the BS are arranged with multiple-channel slotted-ALOHA based protocol. Results obtained from analysis showed that with careful deployment of repeaters, throughput of regions of coverage of such repeaters can be increased but with a sacrifice on throughput of the entire systems. Ref [29] investigated the application of repeaters in CDMA networks and presented measurement results showing improved coverage and quality in areas with weak CDMA coverage.
Jungsuek Oh et al [32] used wave-propagation in buildings, based on physics to model and investigate proper placement of repeaters. It was demonstrated that repeaters with more than $30 \mathrm{~dB}$ gain reduces to a large extent deep signal fading by providing a signal component in the multi-path environment that is dominant. To handle the degradation of the repeaters linear performance and enhance both linearity over large power range and efficiency, an introduction of extra hardware to change the phase shift and attenuation in the pre-distorter and adjust the current with respect to input power was proposed in [7]. F. Adelantado et al, [26] presented an analytical model and derived expressions for transmit power requirements and probability of failed connection in CDMA systems with repeaters in a traffic and spatial non-uniformities environment. This facilitated the computation of the maximum acceptable load, fed to the Call Admission Control (CAC) to prevent network overload and ultimately service degradation.

In ref [33] a novel intelligent 5G repeater with intelligent spectrum sensing capabilities capable of selective amplification of only the active channels in the assigned spectrum was proposed. The repeater intelligently finds the spectral peaks by using energy detection method to find spectral peaks above set energy threshold, and amplifies only such occupied spectrum. Energy efficiency challenges in implementing full duplex (FD) relaying in 5G networks was presented in [21] and proposed solutions such as adaptive self-interference cancellation, hybrid relaying mode selection, transmission power adaptation, multi-input multi-output (MIMO) and massive MIMO FD relaying. Other works in the $5 \mathrm{G}$ relaying could be found in [34].

In addition to research efforts on the generations of cellular networks, other works have been done that are not restricted to any class of cellular network, but are 


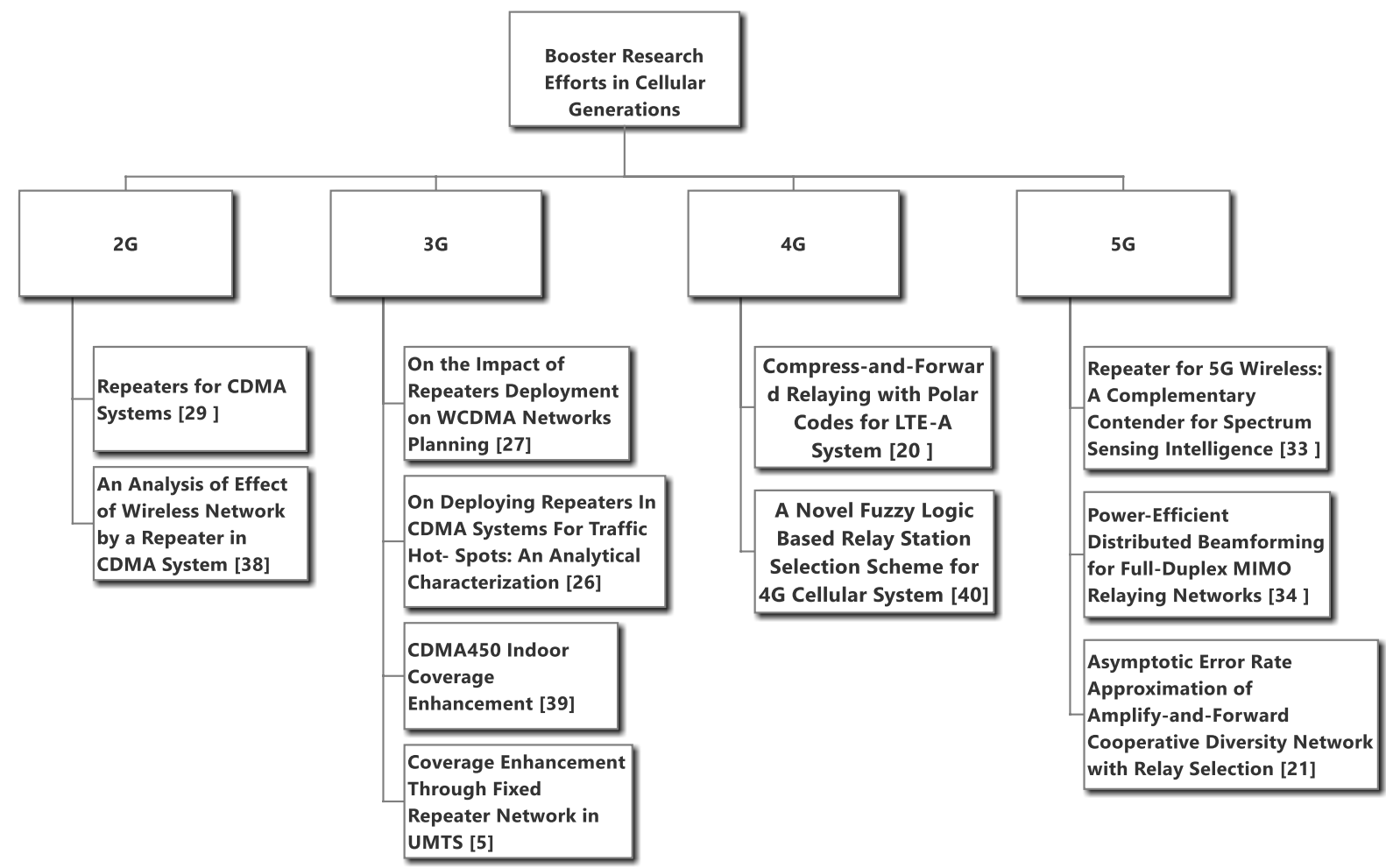

Fig.4. Application of Repeaters on Mobile Network Generations

addressing issues in repeater designs, deployment and analysis. To eliminate the gain limitation and guarantee stability without special donor or transmit antenna, or requiring adequate separation, a cellular repeater was proposed in [3] using adaptive feedback cancellation ensuring ease of installation and usage. The probability of outage for AF and DF relaying in OFDM-based network was minimized in [35] with a proposed relay selection scheme to optimize power allocation and position of relay placement. Similar works are reported in [36,37]. In [40] cellular cell sizes of cellular communication using high altitude platform (HAP) was analyzed to show important factors that affect shape, layout and area during design stage. The authors in [41]

As future work, we intend to design a low cost cellular booster for the Nigerian Telecommunication Market that will cover all mobile networks in the country. This will enable the users of any network to overcome the limitations of WSR at cell edges and in buildings. The design challenges highlighted in this work will be put into consideration, local propagation and environmental factors will be accounted for in this design.

\section{CONCLUSION}

This paper presented a survey of cellular signal boosters. It made a detailed over view of cellular boosters, highlighting its operation, and pointed out issues for consideration in antenna selection. It discussed the design and operational working principles, cost determinants, good and poor booster technologies. It specifically discussed boosters fit for local environments like
Nigerian, and mentioned some basic booster specifications. Research efforts in booster design, deployment and analysis across the generations of mobile communications were outlined and briefly discussed. All of these culminated to a look at future work where a signal booster design for given local environment is considered appropriate.

\section{ACKNOWLEDGMENT}

The telecom. research group, on behalf of Federal University of Technology, Minna, Niger State, appreciates the support of Nigeria Communication Commission (NCC) for this project in which a number of students were trained. This project was funded from grant number NCC/CS/007/15/C/038.

\section{REFERENCES}

[1] C. Azubuike and O. Obiefuna, "Wireless Communication: The Impact of GSM on the Economic Lives of the Nigerian Rural Users," Journal of Educational and Social Research, vol. 4, no. 7, pp. 79-87, November 2014. [Online]. Available: http://mcser.org/journal/index.php/jesr/article/view/5301

[2] G. Liu, F. R. Yu, H. Ji, V. C. M. Leung, and X. Li, "In-Band Full-Duplex Relaying: A Survey, Research Issues and Challenges," IEEE Communications Surveys \& Tutorials, vol. 17, no. 2, pp. 500-524, 2015.

[3] D. R. Morgan and Z. Ma, "A same-frequency cellular repeater using adaptive feedback cancellation," GLOBECOM - IEEE Global Telecommunications Conference, pp. 3825-3830, 2012.

[4] Y. S. Cho, J. Kim, W. Y. Yang, and C. G. Kang, MIMO-OFDM Wireless Communications with MATLAB. 
Wiley Publishing, 2010.

[5] A. H. Ali, "Coverage enhancement through fixed repeater network in UMTS," 2006 International $R F$ and Microwave Conference, (RFM) Proceedings, pp. 407-410, 2006.

[6] M. N. Patwary, P. Rapajic, and I. Oppermann, Dynamic QoS Guarantee with Repeater in Power Controlled WCDMA Urban Environment. Boston, MA: Springer US, 2003, pp. 141-148.

[7] L. Zhang, W. Hong, J. Wang, and J. Zhou, "Low cost solution to enhance performance of CDMA repeater amplifier," Asia-Pacific Microwave Conference Proceedings, APMC, vol. 5, pp. 3-5, 2005.

[8] S. S. Shankari and A. G. Gowtham, "Signal Strength Enhancer," International Journal of Industrial Electronics and Electrical Engineering, vol. 2, no. 2, pp. 16-18, 2014.

[9] Y. Xue, "Amplify-and-forward repeater enhanced random access in single-cell wireless communications," IEEE International Symposium on Personal, Indoor and Mobile Radio Communications, PIMRC, pp. 7-11, 2008.

[10] Z. Zhang, K. Long, A. V. Vasilakos, and L. Hanzo, "Full-Duplex Wireless Communications: Challenges, Solutions, and Future Research Directions," Proceedings of the IEEE, vol. 104, no. 7, pp. 1369-1409, Jul 2016.

[11] A. S. M. Marzuki, A. R. Rahim, B. Mohmd, K. Khalil, A. Naemat, and A. Tee, "Antenna Isolation Considerations in WCDMA Repeater Deployment," in 2006 International $R F$ and Microwave Conference. IEEE, Sep 2006, pp. 347-350.

[12] Z. Wei, X. Zhu, S. Sun, Y. Huang, A. Al-Tahmeesschi, and Y. Jiang, "Energy-Efficiency of Millimeter-Wave Full-Duplex Relaying Systems: Challenges and Solutions," IEEE Access, vol. 4, pp. 4848-4860, 2016.

[13] A. B. Saleh, S. Redana, B. Raaf, T. Riihonen, J. Hämäläinen, and R. Wichman, "Performance of amplify-and-forward and decode-and-forward relays in LTE-advanced," IEEE Vehicular Technology Conference, pp. 1-5, 2009.

[14] O. M. Longe, "Effect of signal strength on handover in GSM networks in Owo, Ondo State, Nigeria," in 3rd IEEE International Conference on Adaptive Science and Technology (ICAST 2011), no. ICAST. IEEE, Nov 2011, pp. [Online]. Available: http://ieeexplore.ieee.org/document/6145166/

[15] M. Kashanianfard and K. Sarabandi, "Directional Full-Duplex RF Booster for $2450 \mathrm{MHz}$ ISM Band," IEEE Transactions on Antennas and Propagation, vol. 65, no. 1, pp. 134-141, Jan 2017.

[16] M. M. Wang, "Dynamic Gain Management for On-Channel Repeaters," IEEE Transactions on Broadcasting, vol. 59, no. 4, pp. 685-692, Dec 2013.

[17] P. M. Cabral, D. P. Ferreira, N. B. Carvalho, and J. C. Pedro, "A Repeater Prototype for the UMTS Network Radio Sub-System."

[18] M. Garcia-Lozano, L. Alonso, F. Casadevall, and S. Ruiz, "Capacity and coverage tradeoff in WCDMA environments with repeaters deployment," Wireless Personal Communications, vol. 40, no. 3, pp. 329-342, 2007.

[19] C. T. Lin, F. S. Tseng, W. R. Wu, and F. J. Jheng, "Joint precoders design for full-duplex MIMO relay systems with QR-SIC detector," 2015 IEEE Global Communications Conference, GLOBECOM 2015, 2016.

[20] N. Madhusudhanan and L. Nithyanandan, "Compress-and-forward relaying with polar codes for LTE-A system," in 2014 International Conference on Communication and Signal Processing. IEEE, Apr 2014, pp. 798-802.

[21] M. Choi, H. Nam, and H. Lee, "Asymptotic error rate approximation of amplify-and-forward cooperative diversity network with relay selection," in 2015 International Conference on Information and Communication Technology Convergence (ICTC). IEEE, Oct 2015, pp. 1336-1341.

[22] Y. Tan, Y. Sun, and D. Lauder, "Automatic impedance matching and antenna tuning using quantum genetic algorithms for wireless and mobile communications," IET Microwaves, Antennas Propagation, vol. 7, no. 8, pp. 693-700, 2013.

[23] A. League, The ARRL Antenna, 2007.

[24] R. Jakubowski, "A new generation of high-power cellular repeaters," in 40th IEEE Conference on Vehicular Technology. IEEE, 1990, pp. 24-28.

[25] T. Isotalo, P. Lhdekorpi, and J. Lempiinen, "Improving HSDPA indoor coverage and throughput by repeater and dedicated indoor system," Eurasip Journal on Wireless Communications and Networking, vol.2008, 2008.

[26] F. Adelantado, O. Salient, and J. Pérez-Romero, "On deploying repeaters in CDMA systems for traffic hot-spots: An analytical characterization," IEEE International Symposium on Personal, Indoor and Mobile Radio Communications, PIMRC, 2006.

[27] M. Garcia-Lozano, L. Alonso, F. Casadevall, S. Ruiz, and L. Correia, "On the Impact of Repeaters Deployment on WCDMA, Networks Planning," 2006 IEEE 63rd Vehicular Technology Conference (VTC 2006), vol. 00, no. c, pp. 466-470, 2006.

[28] D. Rodrigo, E. Diaz, and L. Jofre, "Reconfigurable Pixel-Layer Isolator for Frequency-Tunable On-Frequency Repeaters," IEEE Antennas and Wireless Propagation Letters, vol. 13, pp. 475-478, 2014.

[29] M. Bavafa and H. Xia, "Repeaters for CDMA systems," in VTC '98. $48^{\text {th }}$ IEEE Vehicular Technology Conference. Pathway to Global Wireless Revolution (Cat. No.98CH36151), vol. 2. IEEE, 1998, pp. 1161-1165.

[30] N. C. Commision, "Illegal Usage of GSM Boosters," $2016 . \quad$ [Online]. Available: http://www.ncc.gov.ng/statkeholder/media-public/publicnotices/83-illegal-usage-of-gsm-boosters

[31] ETSI, "ETSI EN 300 609-4," 2000. [Online]. Available: http://www.etsi.org/deliver/etsi_en/300600_300699/3006 0904/08.00.02_60/en_30060904v080002p.pdf

[32] J. Oh, M. Thiel, and K. Sarabandi, "Wave-propagation management in indoor environments using micro-radio-repeater systems," IEEE Antennas and Propagation Magazine, vol. 56, no. 2, pp. 76-88, 2014.

[33] S. K. Sharma, M. Patwary, S. Chatzinotas, B. Ottersten, and M. Abdel-Maguid, "Repeater for 5G wireless: A complementary contender for Spectrum Sensing intelligence," IEEE International Conference on Communications, vol. 2015-Septe, pp. 1416-1421, 2015.

[34] X. Xu, X. Chen, M. Zhao, S. ZHOU, C. Y. Chi, and J. Wang, "Power-Efficient Distributed Beamforming for Full-Duplex MIMO Relaying Networks," IEEE Transactions on Vehicular Technology, vol. PP, no. 99, p. 1, 2016.

[35] W. Lijie, Z. Haitao, Xiyong, and W. Jibo, "Optimizing the performance of OFDM-based cooperative networks by relay selection, power allocation and relay localization," 2010 IEEE International Conference on Ultra-Wideband, ICUWB2010 - Proceedings, vol. 2, pp. 686-689, 2010.

[36] R. N. Braithwaite, S. Carichner, and M. Cope, "Echo cancellation for a wide bandwidth mixed-mode WCDMA/GSM repeater with digital sub-band filtering," 
IEEE Vehicular Technology Conference, no. 4, pp. 1-5, 2009.

[37] D. R. Morgan, M. G. Zierdt, D. A. Gudovskiy, J. Z. Pastalan, and Z. Ma, "FPGA implementation of a same-frequency cellular repeater using adaptive feedback cancellation," ICASSP, IEEE International Conference on Acoustics, Speech and Signal Processing - Proceedings, pp. 4728-4730, 2013.

[38] Sang-Jin Park, Whan Woo Kim, and Bum Kwon, “An analysis of effect of wireless network by a repeater in CDMA system," in IEEE VTS 53rd Vehicular Technology Conference, Spring 2001. Proceedings (Cat. No.01CH37202), vol. 4. IEEE, 2001, pp. 2781-2785. [Online]. http://ieeexplore.ieee.org/document/944107/8

[39] A. S. Mohd Marzuki, S. Selamat, A. T. Md Azlan Tee, A. R. Abdul Rahim, K. Khalil, and A. Naemat, "CDMA450 indoor coverage enhancement," 2011 IEEE International $R F$ and Microwave Conference, RFM 2011 - Proceedings, no. December, pp. 107-110, 2011.

[40] M. Vincent, K. V. Babu, M. Arthi, and P. Arulmozhivarman, "A Novel Fuzzy Logic Based Relay Station Selection Scheme for 4G Cellular System," pp. 158-163, 2016.

[41] Y. Albagory, F. A. Raddady, High-Altitude Platforms Cellular System for Sparsely Populated Areas, I.J. Computer Network and Information Security, MECS Publishers, vol. 4, pp13-20 2014.

\section{Authors' Profiles}

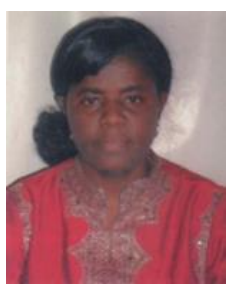

Elizabeth N. Onwuka obtained a Bachelor of Engineering (B.Eng.) Degree from Electrical and Computer Engineering Department, Federal University of Technology (FUT) Minna, Niger State, Nigeria, in October 1992; a Master of Engineering (M.Eng.) Degree, in Telecommunications, from Electrical and Computer Engineering Department, FUT, Minna, Niger State, Nigeria, in March 1998; and Doctor of Philosophy (PhD) Degree, in Communications and Information Systems Engineering, from Tsinghua University, Beijing, People's Republic of China, in June 2004. She is currently a professor in the Department of Telecommunications Engineering FUT, Minna, Niger state. Her research interest includes Mobile communications network architecture, IP networks, handoff management, paging, network integration, and resource management in wireless networks, wireless sensor networks

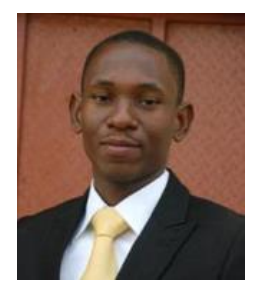

Michael Okwori is a Lecturer at the Department of Telecommunication Engineering, Federal University of Technology, Minna, Nigeria where he obtained his MEng Degree in Communications Engineering and a BEng in Electrical and Computer Engineering in 2007. His Research interests include Mobility Management in IP Networks, Design and Development of Smart Micro Systems and Industrial Internet of Things Sensors.

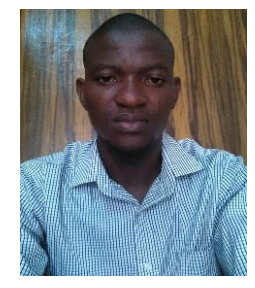

Salihu O. Aliyu is an Assistant lecturer in the Department of Telecommunication Engineering, Federal University of Technology, Minna Nigeria. He received the BEng. degree in electrical and computer engineering at Federal University of Technology, Minna, with a First Class honor in 2010 and M.Sc. degree in Electrical Engineering from the King Fahd University of Petroleum and Minerals, Dhahran, KSA in 2015. From 2011 to 2012, he was a Research Assistant with Manhenrycee Electronics Construction Company, Ilorin Nigeria. His research interests include digital signal/image processing, embedded/intelligent system design, pattern recognition and smart grid.

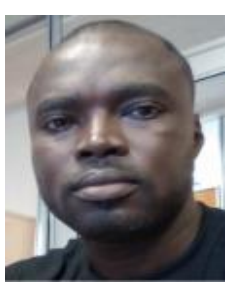

S. S. Oyewobi, is a $\mathrm{PhD}$ student in the department of Electrical Electronic and Computer Engineering, Advanced Sensor Network Group, University of Pretoria. South Africa. He obtained B.Eng Electrical and Computer Engineering in 2003, and M.Eng Electrical Engineering (Telecommunication Option) in 2013 from Federal University of Technology, Minna, Nigeria respectively. His research interest including, Advanced sensor Networks, Energy Managements for network nodes, Industrial wireless Sensors, and internet of things.

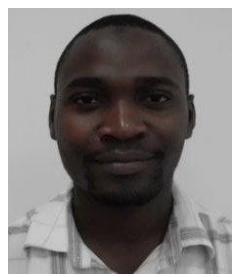

Habeeb Bello-Salau obtained a B.Tech degree in Electronic/Electrical Engineering from Ladoke Akintola University of Technology Ogbomoso, Nigeria in 2009. $\mathrm{He}$ proceeded to International Islamic University Malaysia, Kuala-Lumpur where he received M.Sc degree in Communication Engineering in 2012. He obtained his Ph.D degree in Telecommunication Engineering, from Federal University of Technology Minna, Nigeria. He was an assistant lecturer From November 2011-December 2012 in the department of Electrical and Electronics, School of Technical Education, Niger State College of Education, Minna, Nigeria. He has been a Lecturer II with the department of Telecommunication Engineering, School of Engineering and Engineering Technology, Federal University of Technology Minna, Niger State, Nigeria. He has authored and co-authored more than 11 different research articles in peer reviewed journals and over 15 conference articles. His research interests include Digital Signal and Image Processing, Vehicular ad-hoc Networks, Artificial Intelligence and Wireless Sensor Networks.

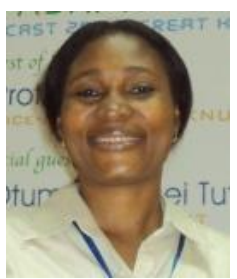

Caroline O. Alenoghena holds a Bachelor of Engineering (1995) and Masters of Engineering (2005) degrees in Electrical/Electronics; she obtained a Doctor of Philosophy $(\mathrm{PhD})$ Degree in Telecommunications Engineering, from the University of Benin, Nigeria in 2014. She is a member of the Institute of Electrical and Electronic Engineers (IEEE), Nigerian Society of Engineers (NSE), and Association of Professional Women Engineers of 
Nigeria (APWEN). She is currently a Senior Lecturer in the Department of Telecommunications Engineering, Federal University of Technology, Minna, Nigeria. Her research interest includes, Radio Network Coverage Optimization, Radio Frequency Spectrum Management, Information and Communication Technology (ICT) Development in Education, Artificial Intelligence in Wireless Communication, and Green Communication.
Sani S. Makusidi and Victor Asuquo are both graduates of the Department of Telecommunication Engineering, Federal University of Technology Minna, Nigeria and both worked on the project of design and development of A Cellular Signal Booster.

How to cite this paper: Elizabeth N. Onwuka, Michael Okwori, Salihu O. Aliyu, Stephen S. Oyewobi, Caroline O. Alenoghena, Habeeb Bello-Salau, Sani S. Makusidi, Victor Asuquo," Survey of Cellular Signal Booster", International Journal of Information Engineering and Electronic Business(IJIEEB), Vol.10, No.6, pp. 21-31, 2018. DOI: 10.5815/ijieeb.2018.06.03 